\title{
What really drove global carbon isotope excursions in deep time? A re- examination of the carbon isotope lever hypothesis
}

\author{
STEFAN V. LALONDE ${ }^{1}$ AND PIERRE SANS-JOFRE ${ }^{2}$ \\ ${ }^{1}$ CNRS-UMR6538 Laboratoire Géosciences Océan \\ ${ }^{2}$ IMPMC, CNRS, Sorbonne Université, MNHN \\ Presenting Author: stefan.lalonde@univ-brest.fr
}

Dramatic and long-lasting excursions in the carbon stable isotope composition of carbonate rocks in deep geological time have historically been interpreted within the " carbon lever " framework [1]. In this model, carbon exit fluxes are divided into two major sinks: (1) organic carbon burial that preferentially sequesters light carbon from the surface environment, and (2) carbonate carbon burial that occurs with only minor carbon isotope fractionation. Positive carbon isotope compositions in carbonates are thus interpreted to represent important carbon burial events, and negative excursions represent events where large amounts of organic carbon were re-mineralized and reinjected into the surface $\mathrm{CO}_{2}$ reservoir. However, significant issues with this framework exist, including weak or absent confirmatory evidence for major organic carbon burial events associated with positive carbon isotope excursions, the implausibly large organic carbon fluxes implicated by both positive and negative excursions, and the fact that in order to maintain $\delta^{13} \mathrm{C}_{\text {carb }}$ values near zero for billions of years, the relative importance of organic vs. inorganic carbon burial must have remained relatively constant over geological time. Here we re-visit the carbon lever hypothesis by taking into account new constraints on the long-term carbon budget that have emerged over the last decade. First we explore the possibility that the carbon lever hypothesis has a significant mass balance problem and that the magnitude of sedimentary sinks (both organic and inorganic carbon) may be insufficient for the maintenance of long term carbon mass balance. Our calculations suggest instead that carbonation of the seafloor has likely played a key role in balancing the long-term carbon cycle. We present a model showing how small changes in carbon isotope fractionation during seafloor carbonation could drive dramatic excursions in the surface carbon reservoir. These results draw into question efforts aimed at reconstructing global biological productivity based on sedimentary carbon isotope records and instead point to strong internal (tectonic) controls over the evolving carbon cycle at Earth's surface.

[1] Holland (1984) The chemical evolution of the oceans and atmosphere. Princeton Univ. Press, NJ. 